\title{
Co-production: Learning from Contexts
}

\author{
Katharine Vincent, Anna Steynor, Alice McClure, \\ Emma Visman, Katinka Lund Waagsaether, \\ Suzanne Carter, and Neha Mittal
}

\begin{abstract}
Given that climate change is a complex, systemic risk, addressing it requires new knowledge. One way of generating such new knowledge is through co-production, or collaborative development by a range of stakeholders with diverse backgrounds embedded in trans-disciplinary processes. This chapter reflects on emerging experiences of co-producing
\end{abstract}

K. Vincent $(\bowtie)$

Kulima Integrated Development Solutions, Pietermaritzburg, South Africa e-mail: katharine@kulima.com

A. Steynor • A. McClure • K. L. Waagsaether

Climate System Analysis Group, University of Cape Town,

Cape Town, South Africa

E. Visman

Centre for Ecology and Hydrology, Wallingford, UK

S. Carter

SouthSouthNorth, Cape Town, South Africa

N. Mittal

University of Leeds, Leeds, UK

(C) The Author(s) 2021

D. Conway, K. Vincent (eds.), Climate Risk in Africa, https://doi.org/10.1007/978-3-030-61160-6_3 
decision-relevant climate information to enable climate-resilient planning and adaptation to climate change in Africa. It outlines principles that have emerged and evolved through experiential learning from a wide range of co-production processes in Africa. It also uses case study experience from various contexts to highlight some of the more contextual challenges to co-production such as trust, power and knowledge systems and institutional factors (mandates, roles and incentives) and illustrates ways that trans-disciplinary co-production has addressed these challenges to mainstream a response to the climate challenge.

Keywords Co-production $\bullet$ Climate services $\bullet$ Adaptation $\bullet$ Climateresilient development $\bullet$ Trans-disciplinarity

\section{INTRODUCTION}

Climate change is a complex, systemic risk and addressing it requires new knowledge. Although in recent years there has been a significant increase in the availability of robust climate information, this has not always translated into effective climate-resilient planning and adaptation. This is often because whilst climate information is being produced, it is not actually usable by decision-makers in practice-instead there is a "usability gap" (Lemos et al. 2012). Recognition of the usability gap has called into question the traditional modes of knowledge production. Rather than the dominant supply-driven models, whereby scientists produce information to fill a knowledge deficit, there is a need for producers and users of information to work together through sustained engagement and iteration to co-produce knowledge that is credible, salient and legitimate (Cash et al. 2003).

Co-production is increasingly promoted as a deliberate approach for increasing the usability of climate services by fostering partnership between "producers" and "users" to create a service that is effectively tailored and targeted (Bremer et al. 2019). The history of co-produced climate services is longer in developed countries, and the practice is still in infancy in the developing world (Kruk et al. 2017). Because it involves a range of partners co-producing context-specific information, there is no blueprint for co-production. In this chapter, we outline some principles to inform 
co-production of climate information. We then illustrate the experiences of three projects within the Future Climate for Africa (FCFA) programme, each co-producing climate information to inform medium term (5-40 years) planning in different contexts: agriculture and cities (African Monsoon Multi-disciplinary Analysis-2050, AMMA-2050), cities (Future Resilience of African Cities and Lands, FRACTAL) and the water-energyfood nexus (Uncertainty Reduction in Models for Understanding Development Applications, UMFULA) (including in partnership with a fourth FCFA project-Integrating Hydro-climate Science into Policy Decisions for Climate-resilience Infrastructure and Livelihoods in East Africa, HyCRISTAL). We end the chapter by discussing some of the more contextual challenges experienced in the three projects, such as trust, power, different knowledge systems and governance factors (mandates, roles and incentives), and how trans-disciplinary co-production has addressed these challenges to mainstream a response to the climate challenge.

\section{Co-production in Climate Services}

Whilst co-production is relatively new in the field of climate change, it has a longer history in other fields where producing salient, credible and legitimate information can be improved by the involvement of users in the process. Public service administration, science policy and science and technology studies, and participatory development are all fields in which knowledge co-production has been applied (Miller and Wyborn 2018).

In all cases, co-production blurs the boundary between "producers" and "users" of information that has typically characterised the linear supply chain. It also challenges the dominance of science and the (explicit or implicit) power differences that often result from those involved in the production or use of scientific outputs. This was a particular motivation behind the participatory turn in development that challenged the supremacy of outside technocratic interventions, instead putting beneficiariesand their priorities and skills - at the centre of the process. Understanding how power is exerted within processes of knowledge-making and use, and with what effects, was also key to the growth of co-production in science and technology studies, where collaborative approaches to problem identification and solution are now a normative goal of much science policy (Wyborn 2015; van Kerkhoff and Lebel 2015). 
Co-production can thus broadly be seen as a collaborative and inclusive set of approaches by producers and users to create usable knowledge to address complex issues such as climate change (Vincent et al. 2018). Also in contrast to the typical supply-driven knowledge deficit model, coproduction is very much an iterative process, requiring regular engagement and trusted relationships between participating parties to be successful. Bearing this in mind, there is no silver bullet for co-production and it can rather be characterised by a number of principles.

\section{Principles of Co-Production}

Various authors have proposed principles of co-production (e.g. Vincent et al. 2018; O'Connor et al. 2019; Norström et al. 2020). Here we outline ten principles of co-production for climate services based on the experiences in FCFA and beyond (Carter et al. 2019) (Fig. 3.1). These principles were derived collectively by five authors based on a review of existing academic literature and practical experiences across a variety of climate services contexts from across a range of climate resilience-strengthening programmes across timescales, including FCFA, and are therefore identified based on experience, or ex-post. They are outlined here before the next section illustrates how some of them were applied in FCFA projects.

\section{Tailor to Context and Decision}

Not only the process, but also the outputs of co-production should reflect the specific context and needs of the decision-making process being engaged. This means understanding the specific user need and decisionmaking context, designing engagements to fit within specific cultural contexts, understanding power dynamics and remaining cognisant (and sometimes humble) about the level of contribution that may result from the process.

\section{Deliver a Timely and Sustainable Service}

In the co-production of climate services, there may be conflicts in the time frames of interest to the various actors involved. Project managers will be dealing with project-related deadlines for the funders; farmers are concerned with time frames related to planting times and timely purchasing of 


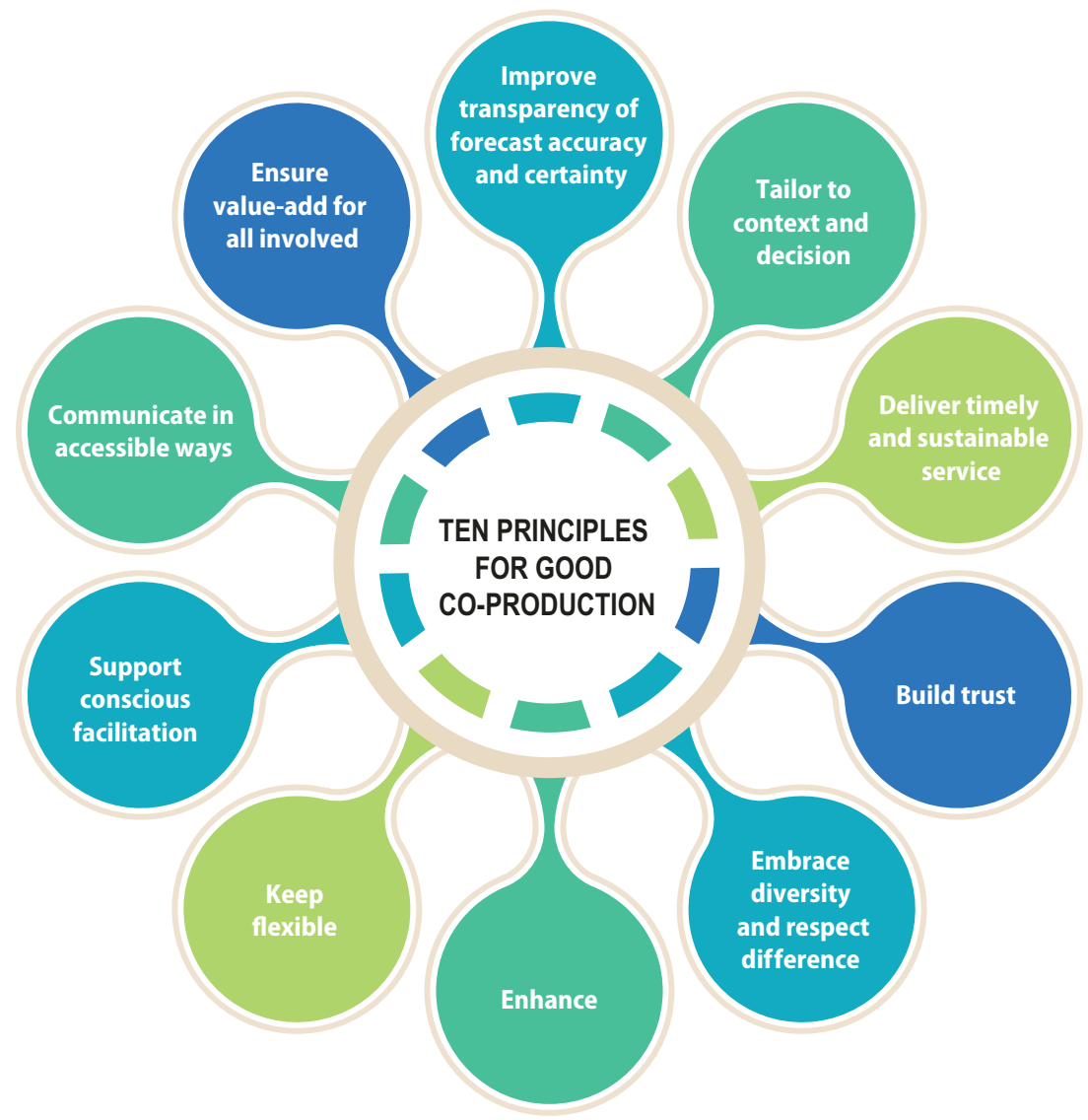

Fig. 3.1 Ten principles for co-production (Carter et al. 2019)

seeds; meteorologists are limited by access to required climate parameters (e.g. sea surface temperature); and policy makers are bound by bureaucratic process and policy development time frames. In order for climate services to be usable, it is also important to align time frames of the forecast to meet the time frames of the decision(s) it is intended to inform. Ensuring timely and sustained availability of funding is necessary to ensure that the process is not linked to a project lifespan. 


\section{Build Trust}

Trust is the cornerstone to any lasting relationship, and is particularly important in co-producing climate services where a number of parties are coming together who may not normally collaborate. Building trust and equitable relationships takes time and often resources, but the resulting trust allows for an increasingly open sharing of ideas, opinions and knowledge needed to truly understand each other's worldviews, positions, strengths and weaknesses. Open dialogue about the intended process and outcomes of co-production is important to build trust. Without trust between partners, the co-production process is, at best, superficial and, at worst, detrimental to any future engagements and/or use of any products that may result from the process.

\section{Embrace Diversity and Respect Differences}

By definition, co-production involves people from different disciplinary and professional backgrounds, each bringing different knowledge and values. Extra effort is required to listen to others and to embrace the skills, ways of working and expertise that others bring to help understand the bigger picture. The benefits of working in a diverse group should be embraced from the beginning and an ethic of respect for differences should be fostered, taking into account that creativity may be required to enable everyone to feel comfortable to share their perspectives. That said, disagreement and debate should be encouraged (in a safe space) because they are often the starting point for new insights.

\section{Enbance Inclusivity}

Truly inclusive stakeholder engagement helps all participants of coproduction feel valued and safe, regardless of their social characteristics and identities, such as gender, age, ethnicity, sexuality and language. Empathy is important; stakeholders should be encouraged to listen to others and understand their perspectives. This might involve being sensitive to historic privileges, prejudices and biases and doing things differently. For example, ensuring that women can participate might require that the timing, location and activities of meetings account for the social norms 
that typically restrict women's input. Without explicit consideration of inclusivity, there is a risk of excluding marginalised or less powerful groups. Inadvertent exclusion of certain user groups would likely reinforce inequality and produce information that is not usable in a particular context.

\section{Keep Flexible}

Co-production is often a non-linear and "messy" process that requires navigation of unknowns. Employing adaptive management, and having the flexibility to change plans, timelines and priorities along the way is critical for a successful co-production outcome. This is often complicated by the fact that diverse partners have varying other priorities and incentives; and the funding mechanisms that underpin co-production are also unlikely to be accustomed to dealing with the need for flexibility and the emergent nature of outcomes.

\section{Support Conscious Facilitation}

Addressing the need to build trust, be inclusive, thorough and flexible requires a process that diffuses power dynamics and hierarchies. It requires recognition of different worldviews and moving beyond the assumed superiority of 'objective' science, to a space where the variety of knowledges and experiences are valued and heard. Ensuring that the coproduction team has members with these skills, or is able to bring them onboard as and when required, is essential.

\section{Communicate in Accessible Ways}

Establishing a common ground amongst the wide range of actors engaged in co-production requires awareness of the different jargons that each party uses and, in many cases, different languages. Co-developing universally understood terminology is important and requires active effort, for example, on the part of information producers, to communicate rather than simply disseminate their outputs. Communication requires an understanding of the way that people experience and perceive climate-related risks, the sources of information that they use and trust and the formats that are most accessible to them. 


\section{Ensure Value-Add for All Involved}

Priorities across the wide range of partners that need to be engaged to coproduce weather and climate services may differ greatly. While researchers may prioritise publishing research, government decision-makers may be concerned with upcoming elections, while private sector bodies may be interested in commercial opportunities and those people directly affected have greater concern for meeting more immediate needs. Differing aims are more likely to be met if they surface early and the process manages to ensure that there is a shared prioritisation in meeting them.

\section{Improve Transparency of Forecast Accuracy and Certainty}

Many climate services involve forecasts and projections of a future state, and are inherently probabilistic. Clearly communicating the confidence and skill of climate information is essential so that it is credible and legitimate in the eyes of users, and does not raise false expectations. Strengthening decision-makers' understanding of key climate concepts and confidence in using probabilistic forecasts enhances capacities to not only use climate information appropriately, but also, more generally, for decision-making under uncertainty.

\section{Case Studies}

Three projects in FCFA employed a range of co-production approaches and we here consider how the approaches embraced the principles that were derived from reflecting on a wider range of projects. Not all of the FCFA projects applied all principles to the same extent-but here we consider how each applied various principles to co-produce climate information to enable adaptation and climate resilient-planning in Africa: in agriculture and cities (AMMA-2050), in cities (FRACTAL) and in the water-energy-food nexus (UMFULA) (including in partnership with a fourth FCFA project, HyCRISTAL).

\section{AMMA-2050}

AMMA-2050 aimed to co-produce information relating to the future functioning of the West African monsoon and how this could inform 
climate-resilient agriculture in Senegal and flood-resilient planning in Ouagadougou, Burkina Faso.

AMMA-2050 employed a suite of methods to support co-production of this climate information. Participatory Impact Pathways Analysis (PIPA) identified the specific problems to be addressed within each pilot, mapping key stakeholders and proposed pathways for addressing these. A serious game known as "Plateau" was used with farmers and farmer networks in Senegal's peanut basin, together with subsequent participatory modelling with (sub-state) regional decision-makers and agricultural researchers to ensure that a bio-economic model appropriately integrated key factors affecting small-holder farmers (Table 3.1). A play was developed encompassing key actors in climate adaptation, including the climate scientist, social scientist, local government, donor, farmer leader and farmers, reflecting key issues identified of concern to the various participants. Performances of the play, known as Theatre Forum and run by a local group, provided platforms for dialogue between key stakeholders in the adaptation process, including climate information producers, agricultural researchers, donors, national and local government and farmer groups (Table 3.1).

Collaboration with another project enabled AMMA-2050 to inform regional and sectoral reviews supporting the development of Senegal's National Adaptation Plan (NAP). Engagement with members of the National Assembly and the Comité Régionale du Changement Climatique (COMRECC), through stakeholder fora and Theatre Forum performances, enabled the project to inform review of national and regional development plans. In Burkina Faso, a café scientifique and ongoing consultations with Ouagadougou's mayoral offices and the Ministry of Town Planning and Housing enabled the development of Intensity Duration Frequency curves and flood-risk maps to inform city planning and infrastructural investments, with the project's outputs also acting as inputs to supporting Burkina Faso's NAP (Table 3.1).

\section{FRACTAL}

FRACTAL aimed to advance scientific knowledge about regional climate responses to human activities and to co-produce knowledge with relevant stakeholders to support resilient development pathways in southern African cities. FRACTAL aimed to do things differently from the start, focusing first on understanding the decision context and allowing climate 
Table 3.1 Selected methods and techniques employed in FCFA projects to enable collaboration

\begin{tabular}{|c|c|c|}
\hline Method & Brief description & Project \\
\hline $\begin{array}{l}\text { Participatory } \\
\text { Impact Pathways } \\
\text { Analysis (PIPA) }\end{array}$ & $\begin{array}{l}\text { Comprising a series of tools, including problem tree } \\
\text { analysis, network mapping, visioning and outcome logic } \\
\text { models, PIPA is an adaptable approach through which } \\
\text { partners jointly develop pathways to achieve agreed } \\
\text { project aims }\end{array}$ & $\begin{array}{l}\text { AMMA- } \\
2050\end{array}$ \\
\hline $\begin{array}{l}\text { Games } \\
\text { (including } \\
\text { Plateau) }\end{array}$ & $\begin{array}{l}\text { Serious games provide a space for experiential learning } \\
\text { that contribute to unpacking relevant issues, grappling } \\
\text { with different perspectives, understanding complex } \\
\text { phenomena, as well as comparing terminology and } \\
\text { concepts in a collegial environment. In the Plateau game, } \\
\text { each plateau-or board-represents the fields of several } \\
\text { farmers. Farmers choose their activities and allocate their } \\
\text { resources, with output dependent on both their decisions } \\
\text { and the 'climate card', giving rain distribution across the } \\
\text { boards. Participants propose options on how to meet } \\
\text { needs, including collaboration and potential policy } \\
\text { interventions }\end{array}$ & $\begin{array}{l}\text { AMMA } \\
2050 \\
\text { FRACTAL }\end{array}$ \\
\hline $\begin{array}{l}\text { Participatory } \\
\text { modelling }\end{array}$ & $\begin{array}{l}\text { An exploratory space for decision-makers to test the } \\
\text { impacts of different policies and actions and researchers } \\
\text { to better appreciate decision-making contexts and learn } \\
\text { about issues that needed to be considered in modelling }\end{array}$ & $\begin{array}{l}\text { AMMA- } \\
2050\end{array}$ \\
\hline Theatre Forum & $\begin{array}{l}\text { A performance is characterised by three main stages: (1) } \\
\text { Actors play a story inspired by real facts and existing } \\
\text { tensions between actors. (2) A moderator then invites } \\
\text { debate to bring out feelings, interpretations and } \\
\text { proposals to resolve tensions. ( } 3 \text { ) Spectators then come } \\
\text { to replace one or more of the characters to test possible } \\
\text { solutions and collectively discuss them. The other actors } \\
\text { remain in character, improvising their responses }\end{array}$ & $\begin{array}{l}\text { AMMA- } \\
2050\end{array}$ \\
\hline café scientifique & $\begin{array}{l}\text { A world café, where researchers host a series of small- } \\
\text { group discussion tables, each focused on sharing a } \\
\text { specific decision-making tool or research output, while } \\
\text { small groups of decision-makers move between the tables } \\
\text { to discuss and provide feedback on each product }\end{array}$ & $\begin{array}{l}\text { AMMA- } \\
2050\end{array}$ \\
\hline
\end{tabular}


Table 3.1 (continued)

\begin{tabular}{lll}
\hline Method & Brief description & Project \\
\hline $\begin{array}{l}\text { City learning } \\
\text { labs }\end{array}$ & $\begin{array}{l}\text { Facilitated events that bring together a broad range of } \\
\text { stakeholders to constructively engage with complex } \\
\text { 'burning issues' (Arrighi et al. 2016). Different } \\
\text { knowledge types, experiences, emotions, identities and } \\
\text { values of people from various backgrounds are equally } \\
\text { valued in the learning labs. Facilitators include a variety } \\
\text { of methods to support sharing of voices from as many } \\
\text { stakeholder groups as possible }\end{array}$ & FRACTAL \\
$\begin{array}{l}\text { Semi-formal events that aimed to share 'snapshots' from } \\
\text { city learning processes (e.g. from the learning labs) with } \\
\text { breakfasts }\end{array}$ & FRACTAL \\
& $\begin{array}{l}\text { opportunity to learn about and shape these processes } \\
\text { Dedicated spaces in which researchers and stakeholders } \\
\text { Collaborative }\end{array}$ & UMFULA \\
learning fora & $\begin{array}{l}\text { could come together to brainstorm and iterate emerging } \\
\text { ideas on the form of the model }\end{array}$ & \\
& & \\
\hline
\end{tabular}

information needs to emerge over time. Co-production methods, implemented over three years, included exploratory city learning labs, field trips, games, roleplays, social evenings, training events, high-level breakfasts and very honest discussions about knowledge generation, evidence and assumptions (Table 3.1 (Arrighi et al. 2016). These methods supported a climate information distillation process described in Chap. 2. Together these activities enabled a space to co-define each city's unique issues, co-explore climate change risks and co-identify opportunities for resilience. Methods used in the co-production process included some that are less frequently used.

Stakeholders from local and national government, NGOs, research organisations and civil society groups generated knowledge on climate risks in the local development context of southern African cities through these trans-disciplinary co-production activities. This knowledge has variously been used in the cities. Lusaka's updated Strategic Plan (2017-2021), for example, integrates climate change considerations with explicit mention of FRACTAL in the acknowledgements from the Town Clerk (Chap. 7). Maputo Municipality is establishing an urban resilience hub and has requested specific support from their local university partner in the FRACTAL project. The City of Windhoek led the development of an Integrated Climate Change Strategy and Action Plan (ICCSAP) and, 
acknowledging the benefits of the integrated approach, decision-makers in Windhoek are hoping to institutionalise collaborative, co-learning platforms to continue exploring climate risks and solutions with a wide variety of stakeholders.

\section{UMFULA}

UMFULA aimed to address the "usability gap" between climate science producers and users to provide more useful and usable climate information to inform medium-term (5-40 year time frame) decision-making in the water-energy-food nexus in Malawi (and Tanzania), and medium- to long-term decision-making in the tea sector in Malawi (and Kenya with HyCRISTAL). The motivation for co-production came from consultation among producers and users in Malawi (Vincent et al. 2014). Government technical staff in the water sector (e.g. in the Ministry of Agriculture, Irrigation and Water Development) reported that they did not know how to use outputs from Global Climate Models, despite being motivated to act on climate change (Pardoe et al. 2018). The Department of Climate Change and Meteorological Services (DCCMS) also identified challenges they face in being able to meet increasing demands for information from government departments with a very slim organisational structure and significant pressure on staff resources.

Members of the UMFULA team worked with different stakeholders to co-produce three main outputs. Together with the DCCMS they developed future climate scenarios, the content and presentation of which was informed by users' needs (Mittal et al. 2017). Together with the Ministry of Agriculture, Irrigation and Water Development, and other stakeholders concerned with water availability, they co-produced an open access Water Evaluation And Planning system (WEAP) model that projects future water availability under a range of socio-economic and climate scenarios (Bhave et al. 2019). This partly took place through collaborative learning fora (Table 3.1). They also co-produced tailored information for the tea sector in Malawi and Kenya, focusing on crop- and location-specific climate metrics of interest, namely the future risk of heat stress (defined as five consecutive days exceeding $35^{\circ} \mathrm{C}$ in Malawi, and exceeding $27^{\circ} \mathrm{C}$ in Kenya) (FCFA 2019). 


\section{Identifying AND Overcoming Challenges}

Although each project worked in different contexts, co-producing climate information using different methods, reflection by the authors as participant observers in the co-production processes, together with more formal evaluation of the tools, showed that they all encountered a number of similar issues. These included trust; power and the challenge of representing different forms of knowledge; and institutional factors: roles, mandates and incentives.

\section{Trust}

Building trust is a critical component of co-production, as outlined earlier, yet has its challenges. Trust was built in various ways by the three projects presented here. Since the co-production process is time- and labourintensive, to a certain extent trust accrues passively throughout the time of repeated engagements and as interpersonal relationships are built. In UMFULA, for example, one of the criticisms that arose early on was that representatives of many scientific research projects would appear at the start of their time frame and then not be heard from again until the end of the project. To avoid this, the team undertook an early process of stakeholder mapping which not only included identifying who had an interest in the climate information and the nature of their interest, but also how they would like to be kept engaged over the four-year duration. One-page updates were produced every six months and distributed as per stakeholder preferences (e.g. electronic or hard copy) and team members made a concerted effort to keep in touch with those people that had stated preference for face-to-face contact. Interpersonal relationships are a prerequisite for trust, and a key component of the credibility of a process, but co-producing climate information also requires building of trust in the generation and use of the information itself.

Trust in the legitimacy of information is particularly important, given the scientific complexity of climate information and the uncertainty that is embodied in generating future projections. This requires meaningful and relevant communication of the uncertainties within climate information, and evaluating levels of understanding to assess the effectiveness of communication approaches employed (Harold et al. 2019). Having identified low levels of confidence in the ability of key stakeholders to understand climate projections led UMFULA to produce a series of short briefs 
directly addressing challenges identified by users, for example, "Climate models: what they show us and how they can be used in planning" (FCFA 2016) and "How to understand and interpret global climate model results" (Conway et al. 2017). These increased the confidence of the stakeholders to engage in further discussions around climate information. In contrast to UMFULA, AMMA-2050 and FRACTAL have employed different methods to strengthen decision-makers' understanding concerning key climate concepts. AMMA-2050 supported direct dialogue between climate information producers and decision-makers. This included a workshop on climate information held in Burkina Faso in partnership with another resilience-building programme to support local government planning and a meeting with Mayors and Ministry representatives. FRACTAL conducted learning labs and placed embedded researchers in each city's planning department, enabling ongoing dialogue, including capacity to answer questions relating to the generation, use and limitations of climate information (Chap. 7).

Successfully building trust through interpersonal relationships and credibility of information was not without challenges. Turnover of staff in planning positions in government (sectoral ministries or city administrations) is relatively rapid. Confronting fluidity of participants within the co-production process meant that progress was not always linear. It was also time- and resource-intensive to develop and maintain the trust required for effective co-production.

\section{Power and Respecting Different Forms of Knowledge}

For co-production to be successful, the process needs to recognise and embrace different forms of knowledge (e.g. scientific, indigenous and experiential) and flatten the power hierarchies that usually accord relatively different levels of value to those different knowledge systems. What makes these power differences particularly difficult is that the values and (mis)perceptions come from all parties. In our cases, by virtue of being interested in co-producing climate information, there was typically an awareness and openness on the part of the "producers" of climate information to other forms of knowledge. However, having seen the greater value placed by society on scientific knowledge, the "users" may inadvertently also assume superiority of those knowledge systems, even if those engaged in that system did not perpetuate it. Sometimes this results in a co-production process having to address the expectation from users that 
producers uniquely have the answers to solve their problems. In short, all parties need to be aware of different ways of knowing and being in the world, and be willing to question the dominant modes to actively coproduce knowledge together.

Different ways of engaging can help to address these power imbalances, with the innovation of the engagement forum signalling a change from the norm in knowledge systems. If a meeting room is set up with a projector and producers talking to users, for example, it can reiterate the superiority of science (as well as being insensitive to the cultural specificity of participation, e.g. Roncoli et al. 2011). All three FCFA projects tried to create these new spaces to sidestep existing (mis)perceptions of power dynamics, by emphasising the importance of collective learning in spaces where equality and inclusion of opinions was promoted, with UMFULA holding collaborative learning fora and FRACTAL holding learning labs. AMMA-2050 employed PIPA and Theatre Forum to support a level platform for dialogue between different stakeholders. Performances of the play with different audiences-including members of the National Assembly, the Institut Sénégalais de Recherches Agricoles (ISRA), with (sub-state) regional decision-makers and farmers' networks-provided opportunities to identify and explore different perceptions, priorities and potential solutions.

Knowledge systems are one element of power, but the experience of co-producing climate information identified other elements of relational power that are socially constructed and culturally specific. Attempting to flatten power hierarchies in knowledge systems is embedded within relational power systems in which that knowledge plays out. Hierarchies are often very important in governments in sub-Saharan Africa (e.g. Pardoe et al. 2018). FRACTAL experienced some tensions during engagements when attempts at levelling the playing field led to researchers using language to address government participants in the room that was sometimes too familiar or casual and disrespectful of their status. In UMFULA, the team adopted multiple layers of engagement: in addition to regular technical discussions, senior researchers would liaise with directors to maintain high level strategic links (and the required support for the continued success of the technical links).

In short, dealing with power issues, whether they be related to knowledge types, work or cultural norms, gender or historic oppression, might require uncomfortable conversations and careful facilitation. These should 
be seen as part of the co-production process, and a critical prerequisite for co-production to proceed effectively.

\section{Institutional Factors: Roles, Mandates and Incentives}

Co-production requires a different way of operating, which does not always sit easily with existing institutional mandates and incentive structures. The process is so critical to the product (in the form of usable climate information) but is very time-consuming and labour-intensive. This creates demands on both the side of the user and the producer. For the user, co-production creates significant demands on already-pressured staff resources in public sector environments; whilst for the producer, the incentive structures and recognition (for promotion and professional development) do not yet provide sufficient recognition of knowledge exchange activities (Dilling and Lemos 2011; Norström et al. 2020).

In UMFULA, commitment to the co-production process was shown by the nomination of a formal desk officer within the DCCMS in Malawi, which played a key role in ensuring partnership with the national meteorological and hydrological service, and also signalled government commitment to other departments who were variously involved in co-producing climate information (e.g. various departments in the Ministry of Agriculture, Irrigation and Water Development). However, significant pressure on limited resources within the DCCMS meant that the nominated desk officer was not always available. FRACTAL experienced a similar issue with their learning labs where, at least in the early days before the utility was proven, there was inconsistent participation which impeded their effectiveness (due to the need to retrace steps). In addition to pressure on limited resources, the key tasks and performance indicators for government staff also meant that attending engagements took time away from their core roles and, in the case of emergency situations (e.g. being summoned by a minister), that would take priority over their participation in co-production. To a certain extent, building trust and ensuring the multiple levels of engagement (including senior researchers with directors) acted to mediate this risk by increasing support and ensuring consistency of participation in engagement processes. In AMMA-2050, two partnering research institutions, ISRA and the West African Science Service Centre on Climate Change and Adapted Land Use (WASCAL), recognised the need to ensure dedicated institutional capacity for science-policy 
and for researchers to have the tools and training to effectively engage with decision-makers.

\section{CONCLUSION}

Co-production requires a new way of operating that challenges norms of knowledge production and the dominance of scientific knowledge systems, instead recognising that user involvement to co-produce knowledge is essential for addressing the climate change challenge. AMMA-2050, FRACTAL and UMFULA all aimed to co-produce climate information for different sectors in different contexts with the aim of improving usability. Illustrating the principles for co-production outlined here, each project applied various methods and techniques which led to increased demand for, and discerning use of, climate information for decision-making.

The process of co-production, and the application of the principles, creates a number of challenges. The experience of three FCFA projects highlighted priority challenges in terms of trust, power and respecting different forms of knowledge, and the role of governance factors-roles, mandates and incentives. Building trust, addressing power and respecting different forms of knowledge require individual commitments to do things differently. But more than individual commitments, institutional change is required to create a conducive environment for co-production to take place (Turnhout et al. 2020).

Research institutions currently insufficiently recognise investments in supporting the understanding and appropriate use of climate products and services through co-production. While this is changing, for example, through the UK Research Excellence Framework and donors' requirements for climate resilience consortia to demonstrate the socio-economic value of research investments, there remains a need to review the way in which their impacts in strengthening climate resilience are monitored and evaluated. To justify investment, it is important to monitor impacts across the co-production process, as opposed to solely the final project output. This monitoring should consider impacts that are often intangible, such as strengthening of personal and professional relationships leading to ongoing collaborations, creating an open flow of information between producers and users of climate information, awareness raising, fostering ownership of climate services products by their users and behavioural change with regard to the use of climate services (Carter et al. 2019). These "soft" changes may lead to more tangible outcomes such as increased 
institutional investment in science-policy and stakeholder engagement, as well as job promotion for researchers championing co-production efforts (Visman 2019).

\section{REFERENCES}

Arrighi, J., Koelle, B., Besa, M. C., Spires, M., Kavonic, J., Scott, D., Kadihasanoglu, A., Bharwani, S., \& Jack, C. (2016). Dialogue for decision-making: Unpacking the 'City Learning Lab' approach. FRACTAL Working Paper 1. Cape Town: University of Cape Town. Retrieved from http://www.fractal.org.za/wpcontent/uploads/2017/03/RCCC-FRACTAL_wps-7-CityLearning-Lab-V4.pdf

Bhave, A. G., Vincent, K., \& Mkwambisi, D. (2019). Projecting future water availability in Lake Malawi and the Shive River basin. FCFA Country Brief. Cape Town: Future Climate for Africa. Retrieved from https://futureclimateafrica.org/wp-content/uploads/2019/07/3124-umfula-weap-v5.pdf

Bremer, S., Wardekker, A., Dessai, S., Sobolowski, S., Slaattelid, R., \& Van der Sluijs, J. (2019). Toward a multi-faceted conception of co-production of climate services. Climate Services, 13, 42-50.

Carter, S., Steynor, A., Vincent, K., Visman, E., \& Waagsaether, K. (2019). Co-production of African weather and climate services. Manual. Cape Town: Future Climate for Africa and Weather and Climate Information Services for Africa. Retrieved from https://futureclimateafrica.org/coproduction-manual

Cash, D. W., Clark, W. C., Alcock, F., Dickson, N. M., Eckley, N., Guston, D. H., Jäger, J., \& Mitchell, R. B. (2003). Knowledge systems for sustainable development. Proceedings of the National Academy of Sciences, 100, 8086. https://doi. org/10.1073/pnas.1231332100.

Conway, D., Vincent, K., Grainger, S., Archer van Garderen, E., \& Pardoe, J. (2017). How to understand and interpret global climate model results. Cape Town: Future Climate For Africa. Retrieved from http://kulima.com/wpcontent/uploads/2017/10/FCFA_GCM-guide-web.pdf

Dilling, L., \& Lemos, M. C. (2011). Creating usable science: Opportunities and constraints for climate knowledge use and their implications for science policy. Global Environmental Change, 21(2), 680-689.

Future Climate For Africa (FCFA). (2016). Climate models: What they show us and how they can be used in planning. Cape Town: Future Climate For Africa. Retrieved from http://kulima.com/wp-content/uploads/2017/10/FCFA_ Climate_Models_WEB.pdf

Future Climate For Africa (FCFA). (2019). The current and future climate of central and southern Africa. What we have learnt and what it means for decision-making in Malawi and Tanzania. Cape Town: Future Climate For 
Africa. Retrieved from http://kulima.com/wp-content/uploads/2020/02/ key-messages-from-the-umfula-project.pdf

Harold, J., Coventry, K. R., Visman, E., Diop, I. S., Kavonic, J., Lorenzoni, I., Jack, C., \& Warnaars, T. (2019). Guide: Approaches to communicating climatic uncertainties with decision-makers. Retrieved from https://futureclimateafrica. org/wp-content/uploads/2019/09/approaches-to-communicating-climaticuncertainties-with-decision-makers_final.pdf

Kruk, M. C., Parker, B., Marra, J. J., Werner, K., Heim, R., Vose, R., \& Malsale, P. (2017). Engaging with users of climate information and the co-production of knowledge. Weather Climate and Society, 9, 839. https://doi.org/10.1175/ WCAS-D-16-0127.1.

Lemos, M. C., Kirchhoff, C. J., \& Ramprasad, V. (2012). Narrowing the climate information usability gap. Nature Climate Change, 2, 789-794. https://doi. org/10.1038/nclimate1614.

Miller, C. A., \& Wyborn, C. (2018). Co-production in global sustainability: Histories and theories. Environmental Science \& Policy. https://doi. org/10.1016/j.envsci.2018.01.016

Mittal, N., Vincent, K., Conway, D., Archer van Garderen, E., Pardoe, J., Todd, M., Washington, R., Siderius, C., \& Mkwambisi, D. (2017). Future climate projections for Malawi. Future Climate for Africa Country Climate Brief. Retrieved from http://www.futureclimateafrica.org/wp-content/ uploads /2017/10/2772_malawi_climatebrief_v6.pdf

Norström, A. V., Cvitanovic, C., Löf, M. F., West, S., Wyborn, C., Balvanera, P., Bednarek, A.T., Bennett, E. M., Biggs, R., de Bremond, A., Campbell, B. M., Canadell, J. G., Carpenter, S. R., Folke, C., Fulton, E. A., Gaffney, O., Gelcich, S., Jouffray, J.-B., Leach, M., Le Tissier, M., Martín-López, B., Louder, E., Loutre, M.-F., Meadow, A. M., Nagendra, H., Payne, D., Peterson, G. D., Reyers, B., Scholes, R., Speranza, C. I., Spierenburg, M., Stafford-Smith, M., Tengö, M., van der Hel, S., van Putten, I., \& Österblom, H. (2020). Principles for knowledge co-production in sustainability research. Nature Sustainability, 1-9.

O'Connor, R. A., Nel, J. L., Roux, D. J., Lim-Camacho, L., van Kerkhoff, L., \& Leach, J. (2019). Principles for evaluating knowledge co-production in natural resource management: Incorporating decision-maker values. Journal of Environmental Management, 249, 109392.

Pardoe, J., Vincent, K., \& Conway, D. (2018). How do staff motivation and workplace environment affect capacity of governments to adapt to climate change in developing countries? Environmental Science \& Policy, 90, 46-53.

Roncoli, C., Orlove, B. S., Kabugo, M. R., \& Waiswa, M. (2011). Cultural styles of participation in farmers' discussions of seasonal climate forecasts in Uganda. Agriculture and Human Values, 28, 123-138. https://doi.org/10.1007/ s10460-010-9257-y. 
Turnhout, E., Metze, T., Wyborn, C., Klenk, N., \& Louder, E. (2020). The politics of co-production: Participation, power, and transformation. Current Opinion in Environmental Sustainability, 42, 15-21.

van Kerkhoff, L. E., \& Lebel, L. (2015). Co-productive capacities: Rethinking science-governance relations in a diverse world. Ecology and Society, 20, 1. https://doi.org/10.5751/ES07188-200114.

Vincent, K., Dougill, A. J., Dixon, J., Stringer, L. C., Cull, T., Mkwambisi, D. D., \& Chanika, D. (2014). Actual and potential weather and climate information needs for development planning in Malawi: Results of a future climate for Africa pilot case study. Retrieved from http://kulima.com/wp-content/ uploads $/ 2011 / 03 /$ Actual-and-Potential-Weather-and-Climate-InformationNeeds-for-Development-Planning-in-Malawi.-Results-of-a-Future-Climatefor-Africa-Pilot-Case-Study.pdf

Vincent, K., Daly, M., Scannell, C., \& Leathes, B. (2018). What can climate services learn from theory and practice of co-production? Climate Services, $12,48-58$.

Visman, E. (2019). Strengthening the development of decision-relevant climate information: The impact of engaging in AMMA-2050 on partnering researchers. AMMA-2050 Impact Case Study.

Wyborn, C. (2015). Co-productive governance: Building relationships between science and governance to connect knowledge with action. Global Environmental Change, 30, 56-67.

Open Access This chapter is licensed under the terms of the Creative Commons Attribution 4.0 International License (http://creativecommons.org/licenses/ by $/ 4.0 /$ ), which permits use, sharing, adaptation, distribution and reproduction in any medium or format, as long as you give appropriate credit to the original author(s) and the source, provide a link to the Creative Commons licence and indicate if changes were made.

The images or other third party material in this chapter are included in the chapter's Creative Commons licence, unless indicated otherwise in a credit line to the material. If material is not included in the chapter's Creative Commons licence and your intended use is not permitted by statutory regulation or exceeds the permitted use, you will need to obtain permission directly from the copyright holder.

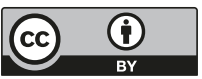

